Dorine Boumans and Johanna Garnitz*

\title{
Ifo World Economic Survey Database - An International Economic Expert Survey
}

\section{Introduction}

The Ifo Institute recently complemented its Ifo World Economic Survey (WES) data set with a special survey on socio-economic characteristics of its respondents. By combining these additional variables, such as professional and academic background, gender and age, with the WES data set new possibilities for research become available. The WES survey has been conducted by the Ifo Institute since 1981, with the overall aim to provide an accurate quarterly picture of the current economic situation, as well as economic trends in over 100 key advanced, emerging and developing economies by polling more than 1,000 economic experts. Unlike official statistics, which are largely based on quantitative information, WES focuses on qualitative information by asking economists for their assessment of selected key economic indicators for the present and for the short-term future. While official statistics on an international basis are only available after a certain time lag and are frequently subject to major revisions, WES results stand out by virtue of the fact that they are rapid, up-to-date and comparable from country to country. The additional dataset with socio-economic characteristics of participants opens new areas of research. This paper describes both the WES and the supplementary data set, sets out the data collection process and the structure of both datasets. In addition this paper gives a short overview of studies that have used the WES, to give an indication of possible research that can be conducted with the WES.

\footnotetext{
*Corresponding author: Johanna Garnitz, Ifo Institute - Leibniz-Institute for Economic Research at the University of Munich e.V., Poschingerstraße 5, 81679 München, Germany, E-mail: garnitz@ifo.de

Dorine Boumans, Ifo Institute - Leibniz-Institute for Economic Research at the University of Munich e.V., Poschingerstraße 5, 81679 München, Germany
}

(c) BY-NC-ND (C) 2017 Boumans and Garnitz, published by De Gruyter. This work is licensed under the Creative Commons Attribution-NonCommercial-NoDerivatives 3.0 License. 


\section{Background - survey based indicators of business cycles}

Survey based indicators have an advantage over official statistics. Official statistics are largely based on quantitative information and are often only available with a considerable time lag. By contrast, survey-based indicators are in most of the cases characterized by qualitative responses, they are quick to establish and predict future developments. Various kinds of survey based indicators exist and in order to give an idea how to classify the WES survey, the next section gives an overview of existing business cycle surveys.

The most common method for economic tendency surveys is questioning firms and businesses or consumers. This approach includes polling a representative share of firms regarding the countries' specific classification of economic activities. Tendency survey are based on qualitative information, as respondents are asked to assign qualities, rather than quantities, to the variables of interest (OECD 2003). Respondents can choose from three simple categories, which can be identified as positive, neutral or negative responses. From these responses a balance statistics, which simply reflects the difference of positive and negative voices, is calculated. One example for a popular business cycle survey that collects qualitative assessments on firm's present business situation and expectations is the Ifo Business Climate Index for Germany (Ifo Institute 2016a). This index is based on approximately 3,000 firms in Germany and their assessment of their present business situation and future expectations. Related, Markit's Purchasing Manager Indices also uses a similar survey method and covers more than 30 industrialised and developing economies (Markit PMI 2016).

Surveys of forecasters, containing expert respondents' predictions of future values of key macroeconomic variables, receive a lot of attention in the financial press, from investors and from policy makers. They are widely perceived to provide useful information about the future state of the economy (Ghysels/ Wright 2009). Surveys that use these expert opinions, like the WES, have the additional benefit that the selection of participants is not focussed on numbers, but rather on the expertise in economic questions of participants. This means that the question of representativeness, which is prominent in business surveys among firms surveys does not apply. The main advantage of these expert surveys is its efficiency - only relatively few experts need to be surveyed to make a relatively precise statement on current and expected economic developments. In surveys among experts both forms of data collection exist, either based on quantitative or on qualitative information. The ECB's Survey of Professional Forecasters (SFP) asks experts about their quantitative forecasts 
for various economic indicators like the real GDP, inflation or the unemployment rate in the euro area (European Central Bank 2016). Consensus Economics, which covers about 85 nations in industrialised countries, Eastern Europe, Asia Pacific and Latin America, can be also counted to surveys among prominent financial and economic forecasters based on quantitative data (Consensus Economics 2016). By contrast, the WES survey belongs to a tendency survey among experts, based on qualitative information. In fact, this methodological approach of globally asking economists qualitative, opinion-related questions on national economic conditions seems to be unique throughout the world. In Germany, however, a similar survey is conducted by the Centre for European Economic Research (ZEW) - the ZEW Financial Markets Survey (ZEW 2016). The ZEW survey has many variables in common with the WES survey (overall economy, inflation rate, short-term and long-term interest rates, stock market and exchange rates). There are however several key differences between the ZEW survey and the WES. The ZEW, in terms of respondents, only includes financial analysts, whereas the WES has a very heterogeneous sample of experts (see Figure 3). The ZEW reports on a monthly basis whereas the frequency of the WES is quarterly. A key advantage of the WES is that it covers more than 100 countries, which is very convenient for international and comparative research purposes.

\section{Ifo World Economic Survey - a first look}

The WES survey collects longitudinal survey data since the 1980s (Stangl 2007; WES 2015). The complementary dataset with socio economic characteristics was surveyed twice, in 2004 and 2014 (MS-WES 2014). The combination of these two datasets offers new areas of research. This section will briefly describe the variables available and the composition of the WES experts.

The WES data is collected for a broad range of countries and includes main macroeconomic variables (assessments and forecasts of the overall economy, private consumption and capital expenditures, developments of the inflation, foreign trade, currencies, interest rates, and the stock market in the months ahead, etc.) as well as variables related to structural policy (most important economic problems, climate for foreign investors, etc.). These data allow for economic, financial and political analysis across countries and time. Kudymowa et al. (2013) showed that the indicators derived from the Ifo World Economic Survey correlate well with the respective business cycle - measured with yearly growth rates of real GDP. This gives an indication of the quality of the data 
collected. The WES database has information on about 30 variables, for over 100 countries, and different aggregates, such as for example the Eurozone, EUcountries or Asian or Latin American countries. These are published on a quarterly basis. Figure 1 shows the country coverage and the average number of participants across the world. This rich dataset can now be combined with socio-economic characteristics of experts, which were collected in two additional surveys in 2004 and 2014 ("WES test 2004" and "WES test 2014"). This includes information on age, gender, education, affiliation as well as sources of information which experts use to form their assessments. Since 2015 the variable type of affiliation of every participant is tracked.

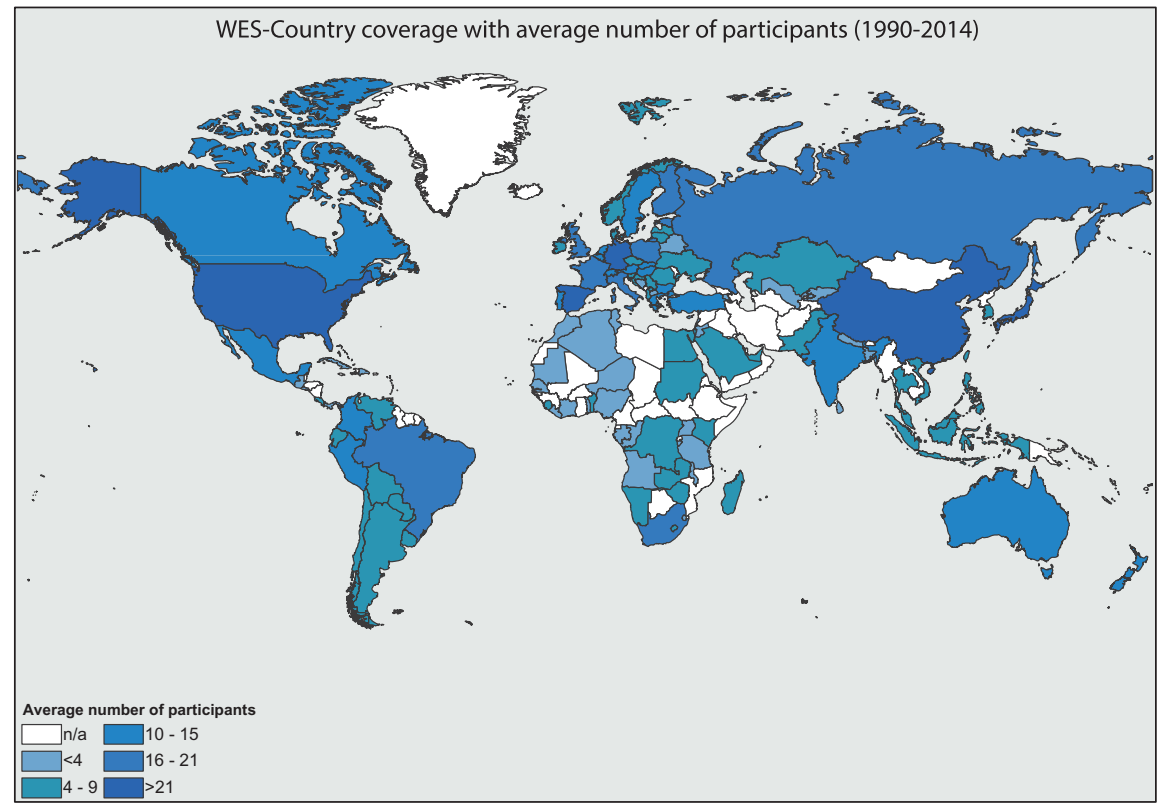

Figure 1: Worldwide country coverage of the Ifo World Economic Survey (WES). Source: Ifo World Economic Survey (WES).

The combination of the results of the two WES tests shows certain changes in the panel composition. As it is common in panel data, not all participants take part in every data point; however as Figure 2 shows, in 1999 there was a remarkable increase in the number of participating experts, which stabilised to about 1,000 from 2005 onwards. Also the number of observed countries increased to around 120 in 2010, this is mainly due to African countries that were included in the panel. 


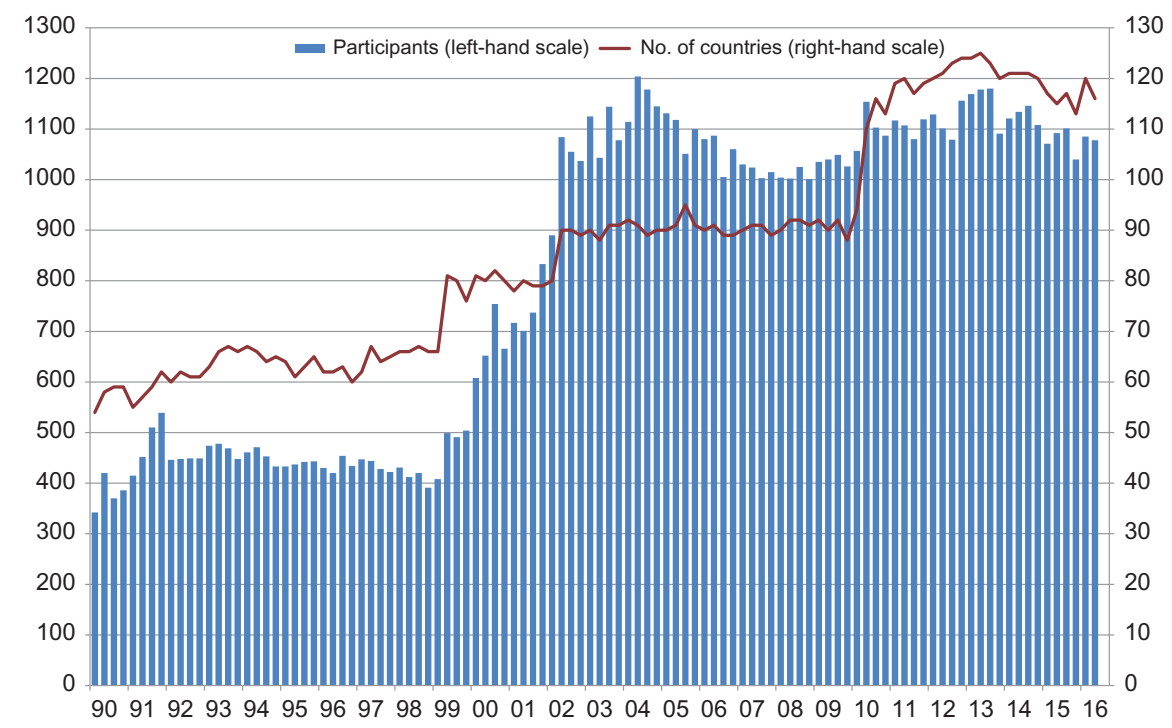

Figure 2: Survey participation of the WES from 1990 until 2016.

Source: Own calculations.

Both WES tests provide information about survey participants and the respective WES panel composition in each year. Table 1 presents socio-economic characteristics of the WES participants and the respective changes since 2004. With respect to gender and age, in 2014 there were no remarkable changes in the panel composition compared to 2004: The share of female/male participants is at $14 \%$ respectively $86 \%$ exactly the same. The age distribution in both years is about one quarter each for the age categories 35-44 years, 45-54 years and 55-65 years. The share of participants aged younger than 35 was at $16 \%$ in 2004 somewhat higher than in 2014 (11\%). By contrast, the share of participants older than 65 is with $13 \%$ twice as high as in 2004 (6\%). With few exceptions, all of the panel members are based in the country that they report on. This is also demonstrated by the fact that $85 \%$ of experts report as citizens (i. e. bear the nationality) of their respective countries. The remaining $15 \%$ are, for example, associated with institutions like embassies/consulates or international organisations that frequently dispatch their staff to a foreign country.

Regarding the distribution in terms of the classification of countries, a glance to the respective shares makes clear, that Ifo made great efforts in involving least developed countries in its survey. The share rose from $0 \%$ in 2004 to over $16 \%$ in 2014. To conclude, in the latest WES test results of least developed economies are included in the sample, contrary to 2004. While there 
Table 1: Descriptive results of WES panelists in 2014 and 2004.

\begin{tabular}{llrr}
\hline & & 2014 (\%) & 2004 (\%) \\
\hline Gender & Female & 13.84 & 14.48 \\
Age & Male & 86.16 & 85.52 \\
& $\leq 34$ & 11.31 & 15.56 \\
& $35-44$ & 25.75 & 27.11 \\
& $45-54$ & 25.48 & 26.89 \\
\multirow{4}{*}{ Nationality } & $55-65$ & 24.52 & 24.89 \\
Questionnaires from Countries & 12.94 & 5.56 \\
& $\geq 66$ & 85.45 & 68.86 \\
& Residents & 14.55 & 31.14 \\
& Non-residents & 48.27 & 52.72 \\
& Advanced economies & 44.80 & 47.28 \\
& Emerging markets and & & \\
Country coverage & developing economies & 6.93 & 0 \\
& Least developed economies & 29.57 & 43.59 \\
& Advanced economies & 53.91 & 56.41 \\
& Emerging markets and & & \\
& developing economies & 16.52 & 0 \\
& Least developed economies & 750 & 459 \\
\hline
\end{tabular}

Source: WES tests 2004 and 2014.

were no major changes in the composition of the WES panel regarding gender and the middle age categories 35-65, there is a slightly different age structure in participants younger than 35 and older than 65 . However, while comparing both results, one should bear in mind, that the response rate for the first WES test was not as high as in the second.

To assess the level of expertise, in terms of academic and professional background of WES experts, in the WES test of 2014 three additional questions were asked: the completed level of education, the field of major degree or studies and the current affiliation. The absolute majority of WES panellists who participated in the WES test have completed tertiary education, while $42 \%$ hold a Ph.D. or a similar level of qualification. This high share of WES participants with a doctorate level of education can be explained by the fact that about one third of WES experts work for research institutes, universities or think tanks. About 16\% work for financial institutions like banks or insurance companies, while $14 \%$ are affiliated with (industrial) companies and around 13\% are representatives of associations or chambers of industry or trade. The remaining $25 \%$ work for national ministries or agencies, central banks, international organisations, embassies or are (private, independent) consultants. 50\% of WES experts majored in or studied "economics". Around 19\% have an academic 
background in business, while $10 \%$ studied natural sciences (mathematics, information technology or engineering). The remaining $17 \%$ studied professional and applied sciences, other social sciences, law or humanities. To conclude, all participants of the WES test enjoyed a higher education. The majority holds a degree in economics. The second frequent field of study is business. Despite this, the WES panel is highly heterogeneous in terms of the institutions to which its experts are affiliated to. However, this heterogeneity, combined with widespread economic monitoring in a large number of countries, gives the WES results a certain added value compared to other business and expert surveys.

There are some striking differences in the composition regarding age and affiliation. For example, in low-income countries there are more experts in the age category 35-44 and less experts within the range of 55-65 years or older, than in the advanced and emerging market group. In advanced economies the age category younger than 34 is less frequent than in developing countries. In least developed countries more experts are affiliated with national ministries or agencies and international organisations and less to financial institutions or associations or chambers (see Figure 3). In turn, in advanced economies more experts are affiliated to non-financial companies and less experts to central banks. The fact, that WES experts in least developed countries have less frequent a major degree in business than in both other groups might be reflected by

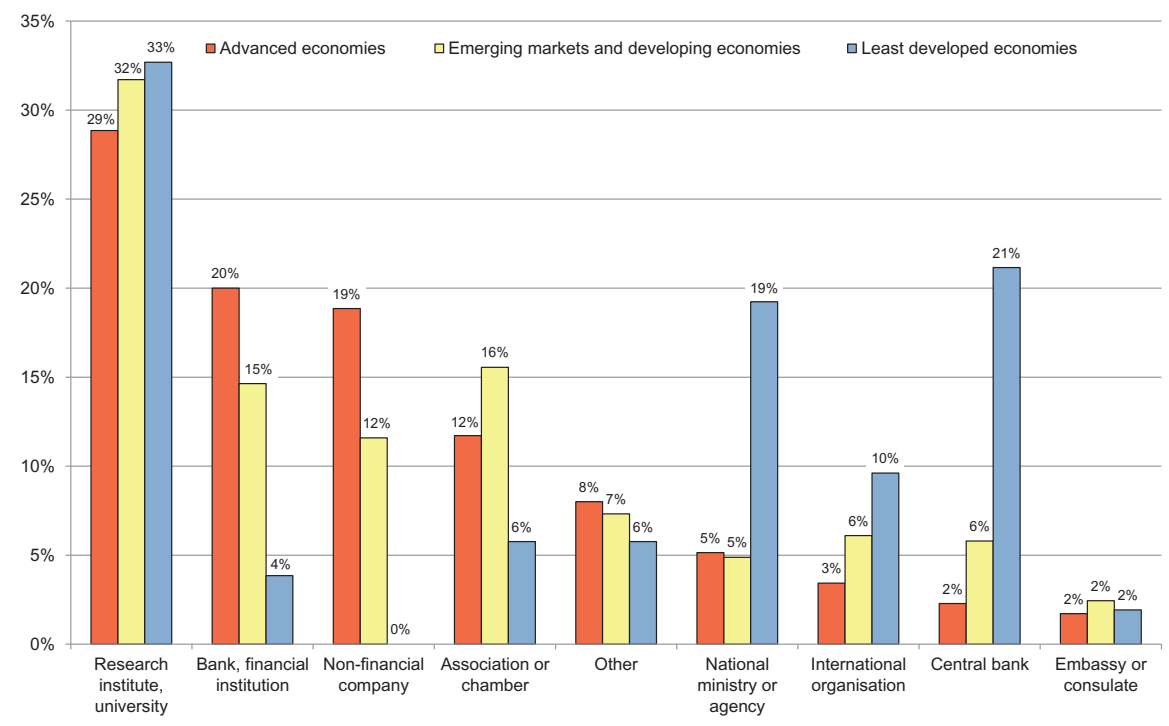

Figure 3: Composition of WES test participants by country classification.

Source: WES test 2014. 
the low share of experts affiliated to non-financial companies. To summarize, the composition of the WES panel is not homogenous by country classification. There are great differences in the distribution regarding age categories, affiliations and studies.

\section{Studies that used the WES}

Every quarter the WES results are published in the journal CESifo World Economic Survey (Ifo Institute 2016b). Besides this Ifo publication, WES indicators have been regularly published in the press and are used by renowned international institutions, such as the OECD and the European Commission (Brunet/Nilsson 2005). Hutson et al. (2014) assessed whether the WES results for the United States were useful in forecasting the directional change of economic variables like GDP, consumption or investment. Koijen et al. (2015) use the WES variables to assess the relationship between survey expectations and the excess volatility across international equity markets. Furthermore, the WES dataset proves to be a rich dataset for dissertation research, see for example Wieland (2013) and Stangl (2009). Recently, also one-time questions asked in the WES have attracted academic interest. For example Steinkamp and Westermann (2014) asked WES experts about their opinion on creditor seniority in Europe's sovereign debt crisis. Potrafke and Reischmann (2016) explored views of economic experts around the world on how to handle the Greek crisis. Boumans et al. (forthcoming) is the first study which uses the WES database with the availability of the socio-economic characteristics on participants to assess biases amongst experts and their views on the effect of terrorism on national economies and the world economy. This shows high potential for a broad range of economic and political analysis, not only through the regular quarterly WES survey, especially now, when this previous data set is matched with the recently made available variables of socio-economic characteristics of its respondents.

\section{Data access}

The WES data and its additional special surveys are freely accessible from the LMU-ifo Economics \& Business Data Center (EBDC), with the restriction that research has to be performed at the EBDC, which is located in the Ifo Institute in Munich. The Ifo Institute strictly holds to its confidentiality policy and is 
committed to guaranteeing the secrecy of obtained survey data. Neither the name of the expert nor of the participant's institution is displayed in the micro data.

Researchers, who are interested in using WES microdata in relation to a clearly specified research topic, should contact the EBDC ${ }^{1}$ for further details of the data access concept and the application procedure. Seiler (2012) and Stangl (2007) provide an overview on how to access the respective data.

\section{References}

Boumans, D., J. Garnitz, G. Schulze (forthcoming), Who Has Terror Angst? Perceptions of the Effects of Terror on the World Economy.

Brunet, O., R. Nilsson (2005), Calculation of Normalised Business and Consumer Confidence Indicators and Zone Aggregates, in: Paper for Presentation at the Joint European Comission-OECD Workshop on International Development of Business and Consumer Tendency Surveys in Brussels, 14-15 November 2005.

Consensus Economics (2016), Consensus Economics - Economic Forecasts and Indicators. Available at: http://www.consensuseconomics.com (accessed June 8, 2016).

European Central Bank (2016), ECB Survey of Professional Forecasters SPF. Available at: http://www.ecb.europa.eu/stats/prices/indic/forecast/html/index.en.html (accessed June 8, 2016).

Ghysels, E., J.H. Wright (2009), Forecasting Professional Forecasters, Journal of Business \& Economic Statistics 27 (4): 504-516.

Hutson, M., F. Joutz, H. Stekler (2014), Interpreting and Evaluating CESIfo's World Economic Survey Directional Forecasts. Economic Modelling 38: 6-11.

Ifo Institute (2016a), Ifo Institute. Available at: https://www.cesifo-group.de/ifoHome.html (accessed June 13, 2016).

Ifo Institute (2016b), CESifo Group Munich - CESifo World Economic Survey. Available at: https://www.cesifo-group.de/ifoHome/publications/journals/CESifo-World-EconomicSurvey.html (accessed June 13, 2016).

Koijen, R.S.J., M. Schmeling, E.B. Vrugt (2015), Survey Expectations of Returns and Asset Pricing Puzzles, SSRN Scholarly Paper No. ID 2513701, Social Science Research Network, Rochester, NY.

Kudymowa, Evgenia, J. Plenk, K. Wohlrabe (2013), Ifo World Economic Survey and the Business Cycle in Selected Countries. CESifo Forum 14 (4): 51-57.

Markit PMI (2016), PMI. Available at: http://www.markit.com/product/pmi (accessed June 13, 2016).

MS-WES (2014), Meta Survey for Ifo World Economic Survey 2014, LMU-ifo Economics \& Business Data Center, (Munich). DOI: 10.7805/ebdc-ms-WES-2014.

1 For further information email: mittelmeier@ifo.de or http://www.cesifo-group.de/ifoHome/ facts/EBDC/Databases-and-Support.html 
OECD (2003), Business Tendency Surveys: A Handbook - OECD. Available at: http://www.oecd. org/std/leading-indicators/businesstendencysurveysahandbook.htm (accessed June 14, 2016).

Potrafke, N., M. Reischmann (2016), How to Handle the Crisis in Greece? Empirical Evidence Based on a Survey of Economics Experts, CESifo Working Paper Series, 5860.

Seiler, C. (2012), The Data Sets of the LMU-ifo Economics \& Business Data Center-A Guide for Researchers. Ifo Working Paper.

Stangl, A. (2007), European Data Watch: Ifo World Economic Survey Micro Data, Schmollers Jahrbuch Journal of Applied Social Science Studies/Zeitschrift für Wirtschafts- und Sozialwissenschaften 127 (3): 487-496.

Stangl, A. (2009), Essays on the Measurement of Economic Expectations, Munich Dissertations in Economics No.9823, University of Munich, Department of Economics.

Steinkamp, S., F. Westermann (2014), The Role of Creditor Seniority in Europe's Sovereign Debt Crisis. Economic Policy 29 (79): 495-552.

WES (2015), Ifo World Economic Survey 1983-Q4 2015, LMU-ifo Economics \& Business Data Center, (Munich). DOI: 10.7805/ebdc-wes-2015b.

ZEW (2016), ZEW Financial Market Survey \& ZEW Indicator of Economic Sentiment. Available at: http://www.zew.de/en/publikationen/zew-gutachten-und-forschungsberichte/forschungs berichte/konjunktur/zew-finanzmarktreport, accessed June 8, 2016. 